Technical Report No. 32.1028

\title{
Digital Computer Processing of X-Ray Photographs
}

\author{
R. H. Selzer
}

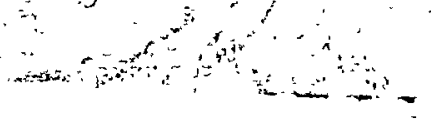

GPO PRICE $\$$

CFSTI PRICE(S)

Har sopy $(\mathrm{HC}) \frac{1-20}{\mathrm{C}}$

11 683 July 05

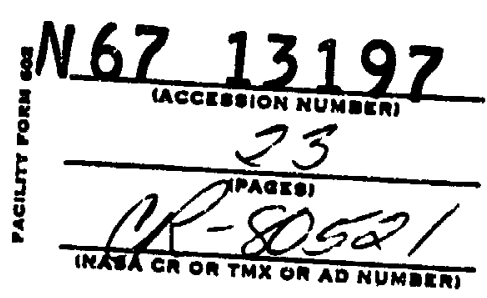

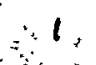

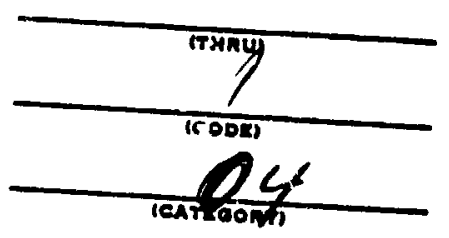

fin: 
NATIONAL AERONALTICB AND BPACE ADMINIBTRATION

Technical Report No. $32-1028$

Digital Computer Processing of X-Ray Photographs

R. H. Selzer

Approved by:

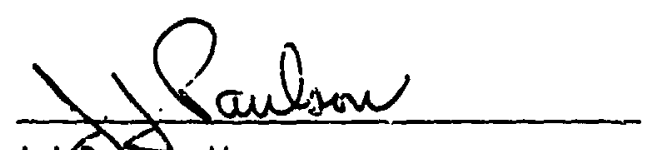

J. J Cansoh, Manager

Space Instrument Systems Section

JET PROPULSION LABORATORY

CALIFORNIA INBTITUTE OF TECHNOLOGY

paeadena. California

November 15, 1966 
Copyright (C) 1966

Jet Propulsion Laboratory

California Instifute of Technology

Prepared Under Contract No. NAS 7,100

National Aeronautics \& Space Administration 


\section{CONTENTS}

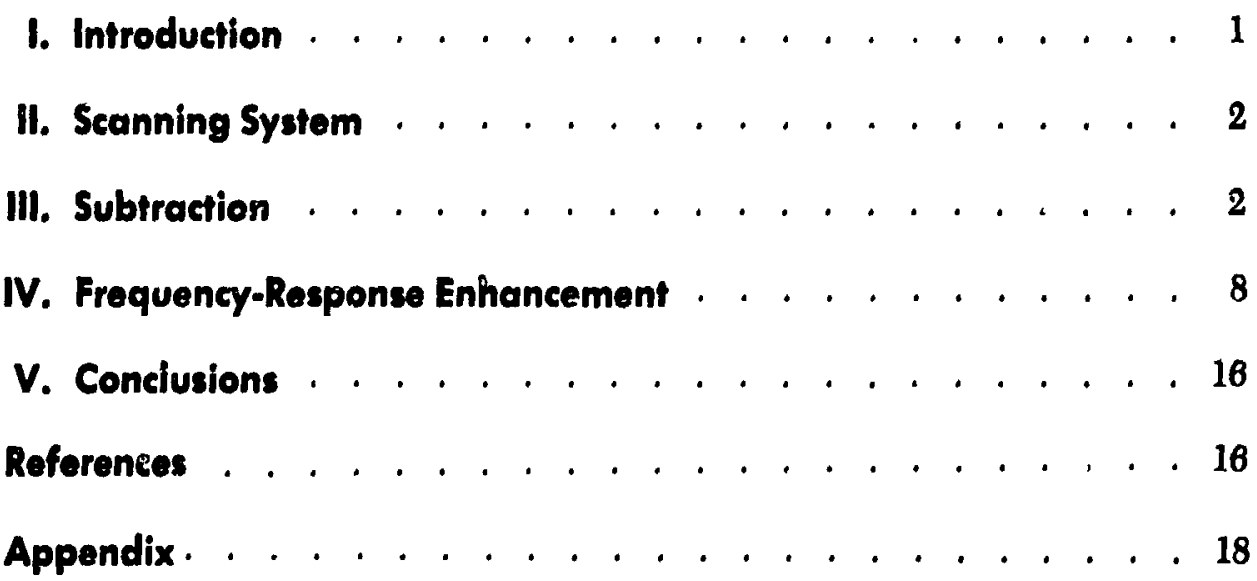

\section{FIGURES}

1. Ranuer 3 ealibration picture before distortion correction . . . . . . 3

2. Ranger 3 callikration piefure after distortion sorrection . . . . . . . 3

3. X-kay of chest taken Fobruary 1954 . . . . . . . . . . . . . 4

4. X-Ray of chest taken Soptember 1954, showing cancer (arrow) . . . . 4

5. X-Ray of chest taken Septomber 1954, aftor application of correction program to maich earliar $x$-ray . . . . . . . . . . . . . . . 5

6. Absolutedifference plefure withouf correction program . . . . . . . 6

7. Absolute-difference pieture ofter sorrection programi . . . . . . . . 6

8. X-Ray of chest taken Soptomber 1954, offer high-pass filfer . . . . . 7

9. Result of subtracting shest $x$-ray of February 1954 from x-ray of September 1954 and sotfing negative differences to zoro (whito) . . . . 7

10. Effect of filter on system transfor funefion . . . . . . . . . . . . 8

11. Angiogram of skull bofore filtering . . . . . . . . . . . . . . 9

12. Angiogram of skull after high-frequeney emphasls filter . . . . . . . $\theta$

13. Infrared photograph of diseasod foot bofore processing . . . . . . . 10

14. Infrared photegraph of diseaced foot aftor high-frequency emphasis filter. . . . . . . . . . . . . . . . . 10

15. Photomierograph of chromosome in metaphase, before processing . . . 11 
JPL TECHNICAL REPORT NO. 32.1028

\section{FIGURES (Cont'd)}

16. Photomicrograph of chromosomo in motaphase, affer high-frequency umphasis filfor . . . . . . . . . . . . . . . . . . . 11

17. Effect of high-pass filter . . . . . . . . . . . . . . . . . . 12

18. Angiogram of skull bofore processing . . . . . . . . . . . . . 13

19. Anglogram of skull affer high-pass filter . . . . . . . . . . . . 13

20. X-Ray of skull showing portion of mastoid solectod for processing (box) . . . . . . . . . . . . . . . . , 14

21. X-Ray of mastoid after digitizing, but bofore filtering . . . . . . . 15

22. X-Ray of mastoid after high-pass filtering . . . . . . . . . . . 15 


\begin{abstract}
The interpretation of medical and biological pictures, such as $x$-ray photographs, can frequently be made easier if selected portions of the image are first enhanced by means of a digital computer. Two particular enhancement methods are described in this Report. The first method uses image subtraction to achieve enhancement by removing unimportant information from the picture. The second method uses two-dimensional filtering to achieve enhancement by emphasizing seiected portions of the picture frequency spectrum. This filtering method is particularly useful for bringing out fine detail that is totally invisible on the unprocessed picture. Examples of enhanced medical x-rays, photomicrographs, and infrared photographs are shown.
\end{abstract}

$$
\text { AUTHOR }
$$

\title{
I. INTRODUCTION
}

For a number of years, digital computers have been used at Jet Propulsion Laboratory to correct various photometric, geometric, and frequency response distortions in the pictures received from the television cameras of the Ranger, Mariner, and Surveyor spacecraft (Ref. 1). Early in 1966, an investigation began into the applicability oi these computer methods to medical and biological photographs, and the initial results of this investigation are presented in this paper.

Broidly spenking there are two types of processing that $: \mathrm{u}$ be performed by a digital computer on a picture. With the first type, which might be called content analysis, the computer extracts information from the picture and presents the resultant information, non- pictorially in most cases. An example of this type is a pattern recognition system in which the output from the processing consists of an indication of which patterns were present (Refs. 2-5).

The second type of picture processing, and the type described in this paper, might be termed image enhancement (Refs. $\theta$ and 7). The objective is an improved picture-improved in the sense that a human photointerpreter can more readily find what he is looking for. This does not necessarily mean that the picture is better photometrically. The photointerpreter may want lower resolution than he began with or he may want a picture with a highly distorted frequency spectrum, depending 
upon the type of picture information he needs and the type he may get. The purpose of this Report is to illustrate some of the things that computer processing can do with a picture so as to better display its information.

After a brief discussion of the scanning system, an explanation is given of a subtraction technique that pro- vides image enhancement by ridding the picture of useless information. The computer provides the flexibility to perform subtractions not possible by conventional methods. Following that, a filtering method is described that allows the Fourier frequency spectrum of the picture to be arbitrarily changed to enhance particular types of data.

\section{SCANNING SYSTEM}

Medical x-ray photographs are converted into a form suitable for input to the computer by means of a cathoderay tube scanner. A light beam is passed through a transparency on a line-by-line basis, converted to an ulectrical signal, and then digitized to a number between 0 and 63 , depending upon the optical density of the transparency at the sampled point. Each sample (typically 500,000 samples for a 1-in.-sq transparency) is recorded on magnetic tape which is subsequently fed into an IBM 7094 computer.

In the past, the largest transparency that could be scanned was $35 \mathrm{~mm}$. Although the system is currently being modified to scan $70 \mathrm{~mm}$ films, most medical x-ray pictures will still have to be photographically reduced before scanning takes place. Since this reduction causes substantial picture degradation, it would be highly desirable to have a system that would directly scan the picture in its original, full size.

After it has been processed by the computer, the picture is converted back into a transparency by means of the cathode-ray tube scanner. Each sample is converted from digital form to an analog voltage which is used to modulate the intensity of an electron beam as it exposes film by a line-by-line scan.

\section{SUBTRACTION}

The technique of subtraction of two x-ray pictures taken at different times, as a means of emphasizing change, is not new (Refs. 8 and 9). The usefulness of the technique when accomplished by optical methods, however, is limited because of the difficulty of obtaining two pictures witt. identical orientation. Closely matched pairs of skull $x$-rays are not difficult to obtain, but matched chest pictures may be difficult to obtain since small differences in the respiratory cycle will cause con- siderable differences in the rib position. However, through the use of a distortion-correction program originally developed for application to the cameras of the Ranger spacecraft, two mismatched $x$-ray photographs may be forced into a match and a subsequent subtrac. tion performed.

Geometric distortion in the Ranger camera was measured simply by photographing a rectangulac screen as 
JPL TECHNICAL REPORT NO. 32-1028

shown in Fig. 1. Distortions, expressed in terms of a point displaced from its true position some number of samples up or down, right or left, were measured at about 100 points on the picture. Subsequent pictures were then corrected by noving samples at the 100 corresponding, measured points to their true position and by moving all intermediate samples proportionately, using linear interpolation. Figure 2 shows the calibration picture after the distortion removal program.

Now consider the application of this program to the pair of chest $x$-rays shown in Figs. 3 and 4. Figure 3 was taken February 1954 and Fig. 4 on September 1954. Note the appearance of the cancer (indicated by an arrow) in the later photo. ${ }^{1}$ A comparison of the rib positions on the patient's right side in the two pictures shows the mismatch. The results of the correction program, based on measurements of 80 points on the patient's right side, are shown in Fig. 5.

After one picture was distorted to match the other, a subtraction was performed on the two pictures point-bypoint. The absolute value of the differences was taken and, after a contrast increase by a factor of four, the results as shown in Figs. 6-9 were obtained. Figure 6

'Noted by William Weiss, MD, on a drawing that accompanied the original chest $x$-ray photographs.

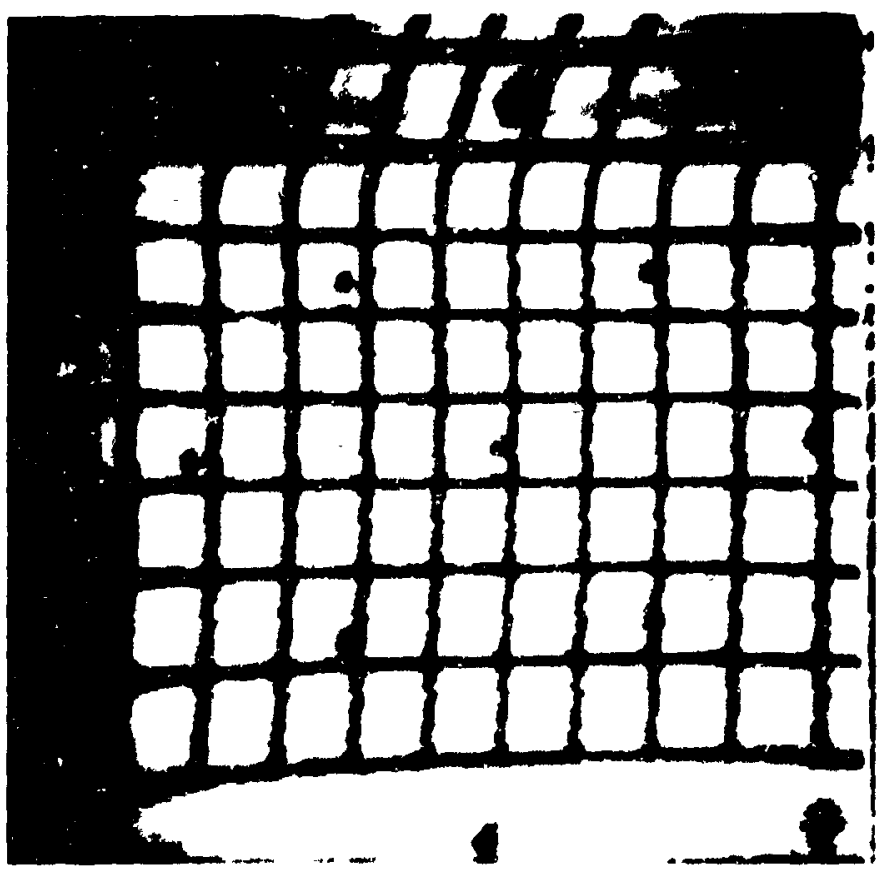

Fig. 1. Ranger 3 calibration piefure before distortion corroction represents the difference picture for the best match that could be obtained strictly by translation and magnification change. Figure 7 represents the same difference after application of the correction program. Note that the cancerous area is more evident on the matched difference.

Since the two pictures were not taken at the same time, it is likely that the conditions for exposure and development were not identical. Thus even a perfect gcomctric match of a physiologically unchanged area might still produce a difference that is not \%ero. For example, the first picture, $1 . ?$ eled $2 / 34$, was substantially darker on the patient's, sis.s side than the other picture, but was lighter on the left side.

To minimize the effect of such differences, a high-pass filter (discussed in detail in th ? next section) was first applied to the pictures. This tended to decrease back. ground variation between the two pictsi 3 . Figure 8 shows the filtered version of the picture labeled $9 / 54$. This should be compared with the unfiltered version in Fig. 4. Figure 9 shows the difference picture where negative differences were set to zero (white). A comparison of the right half of Figs. 8 and 9 shows how the total information in a picture can be substantially reduced by removing information of iow interest.

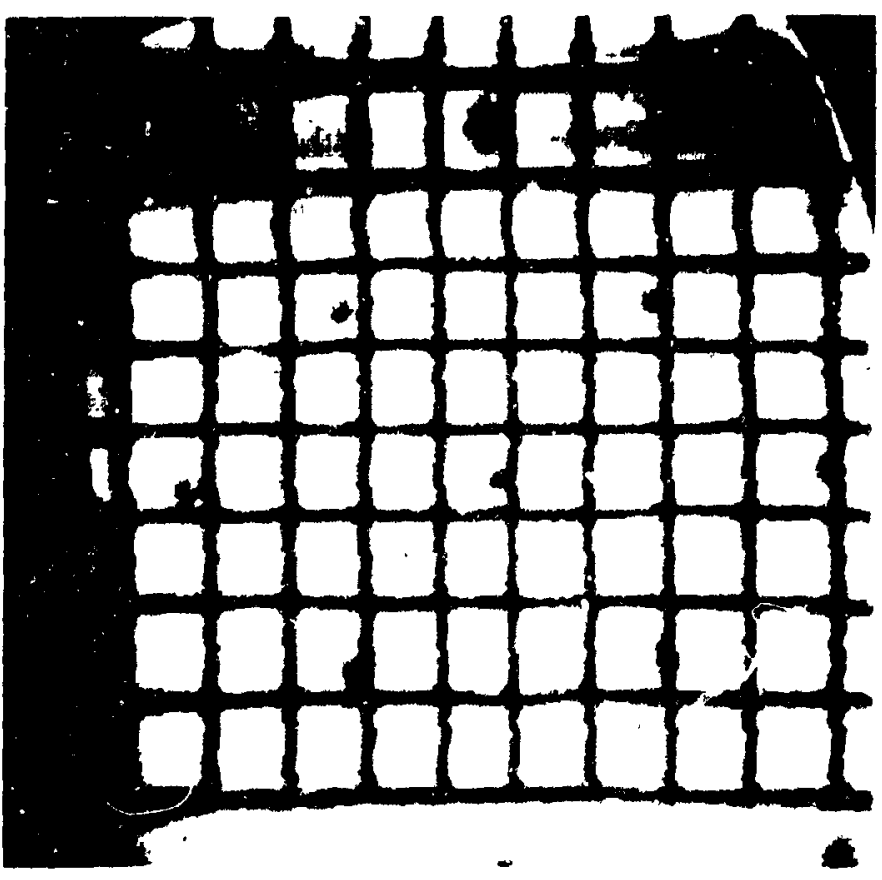

Fig. 2. Ranger 3 calibration pieture after distortion cornection 


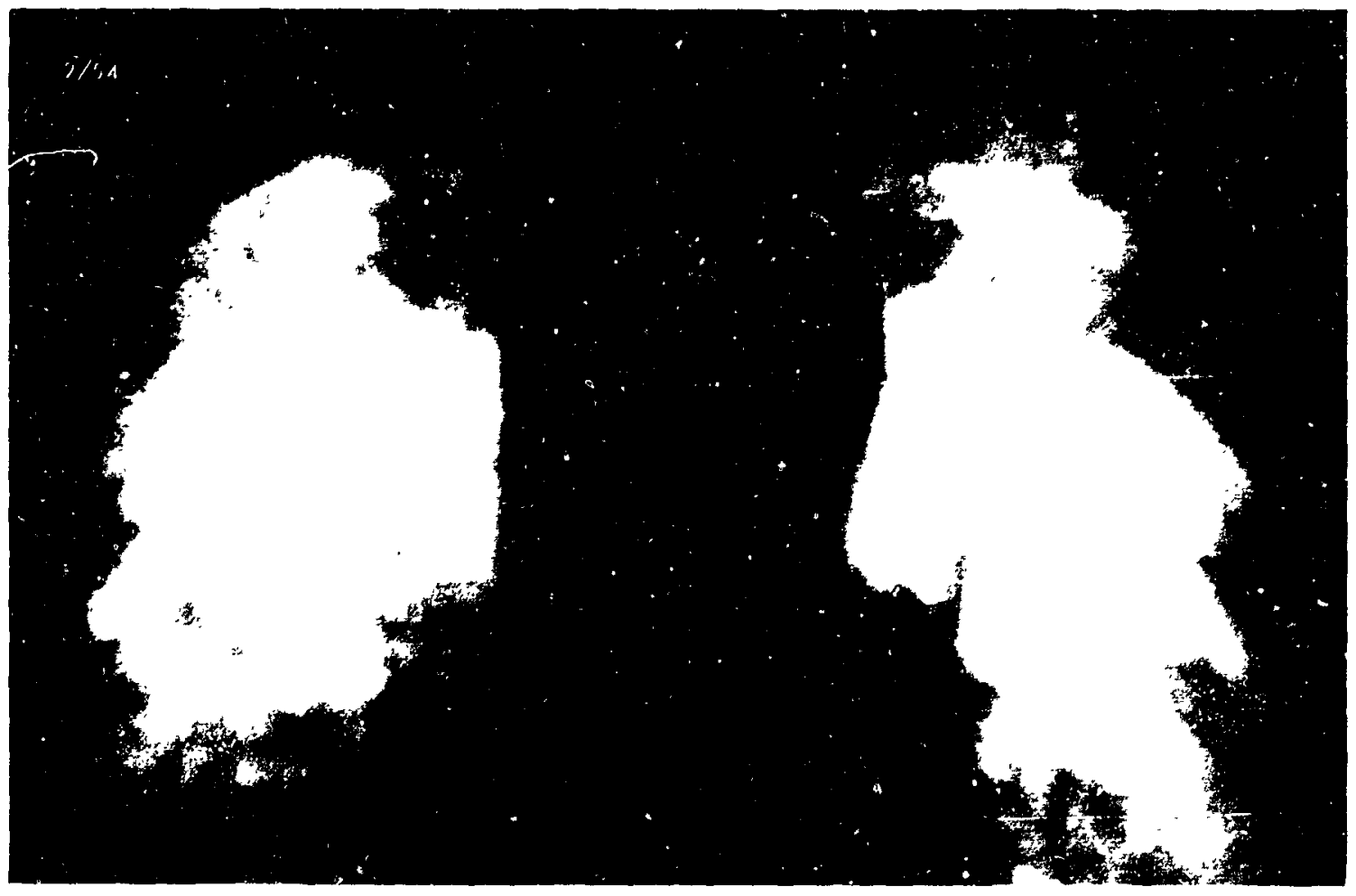

Fig. 3. X-Ray of chest taken February 1954

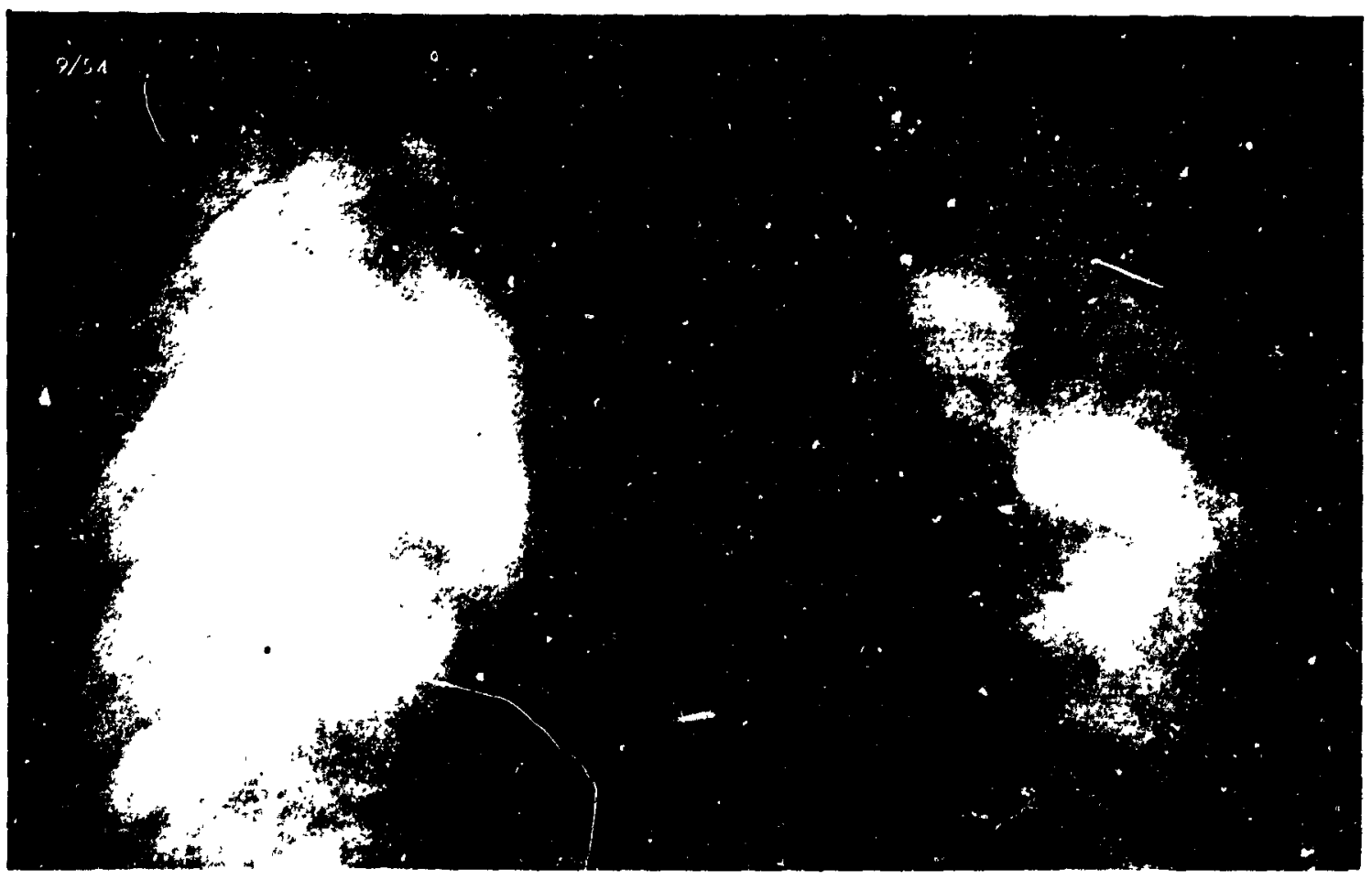

Fig. 4. X-Roy of chest taken September 1954, showing cancer (arrow) 


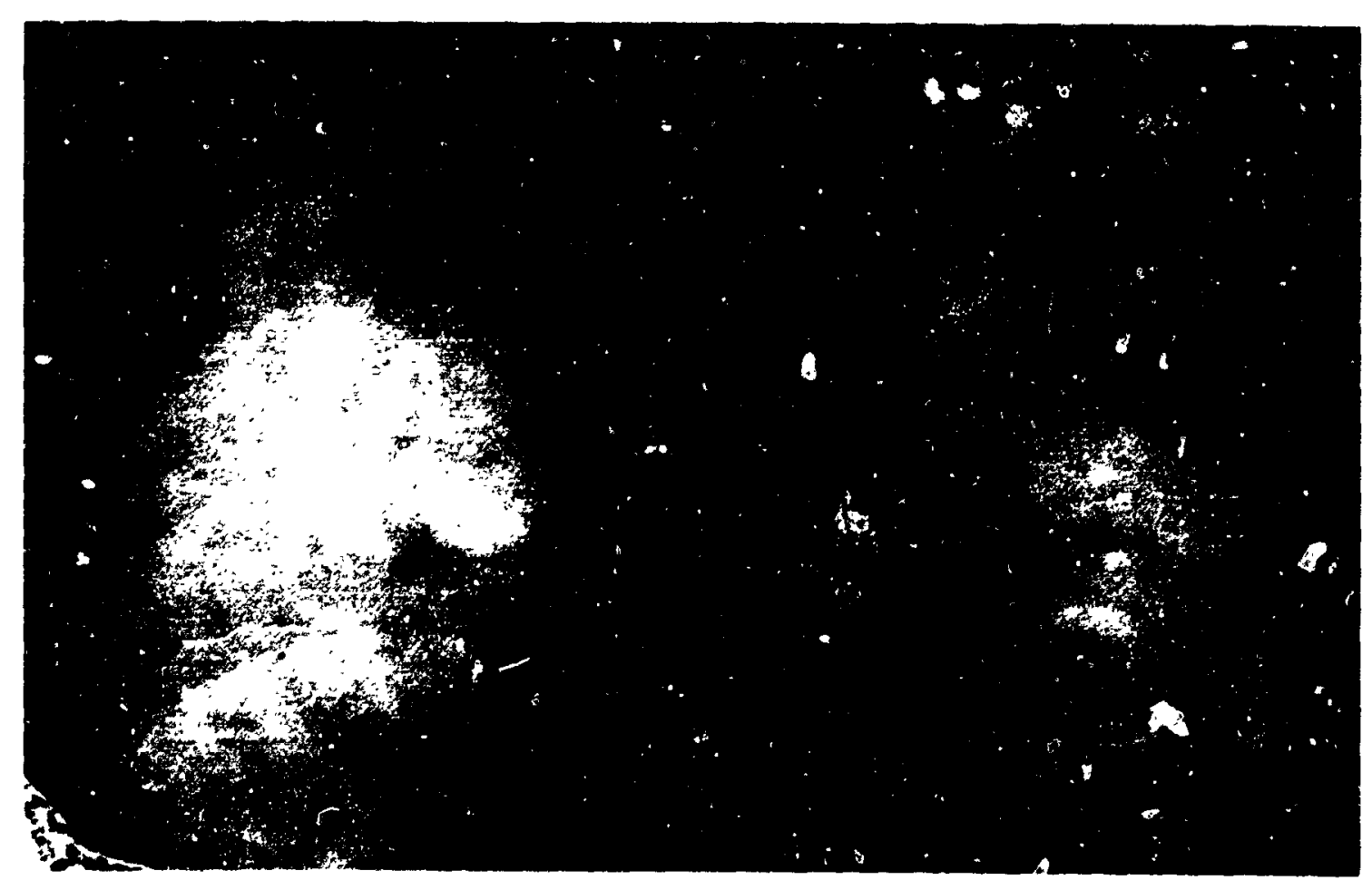

Fig. 3. X-Ray of chest taken Septamber 1954, after application of correction program to match earlier $x$-ray 


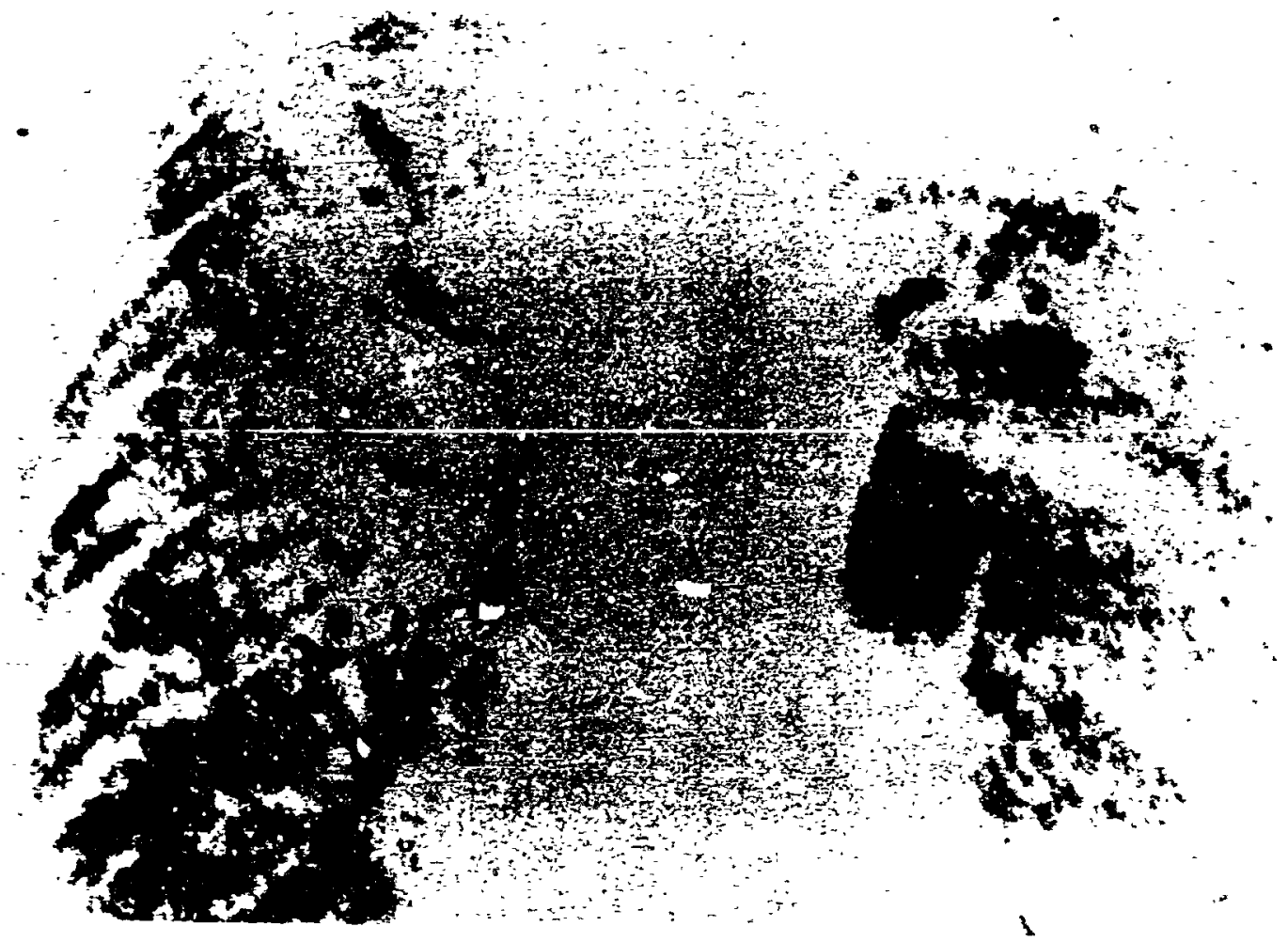

Fig. 6. Absolute-difference picture without correction program

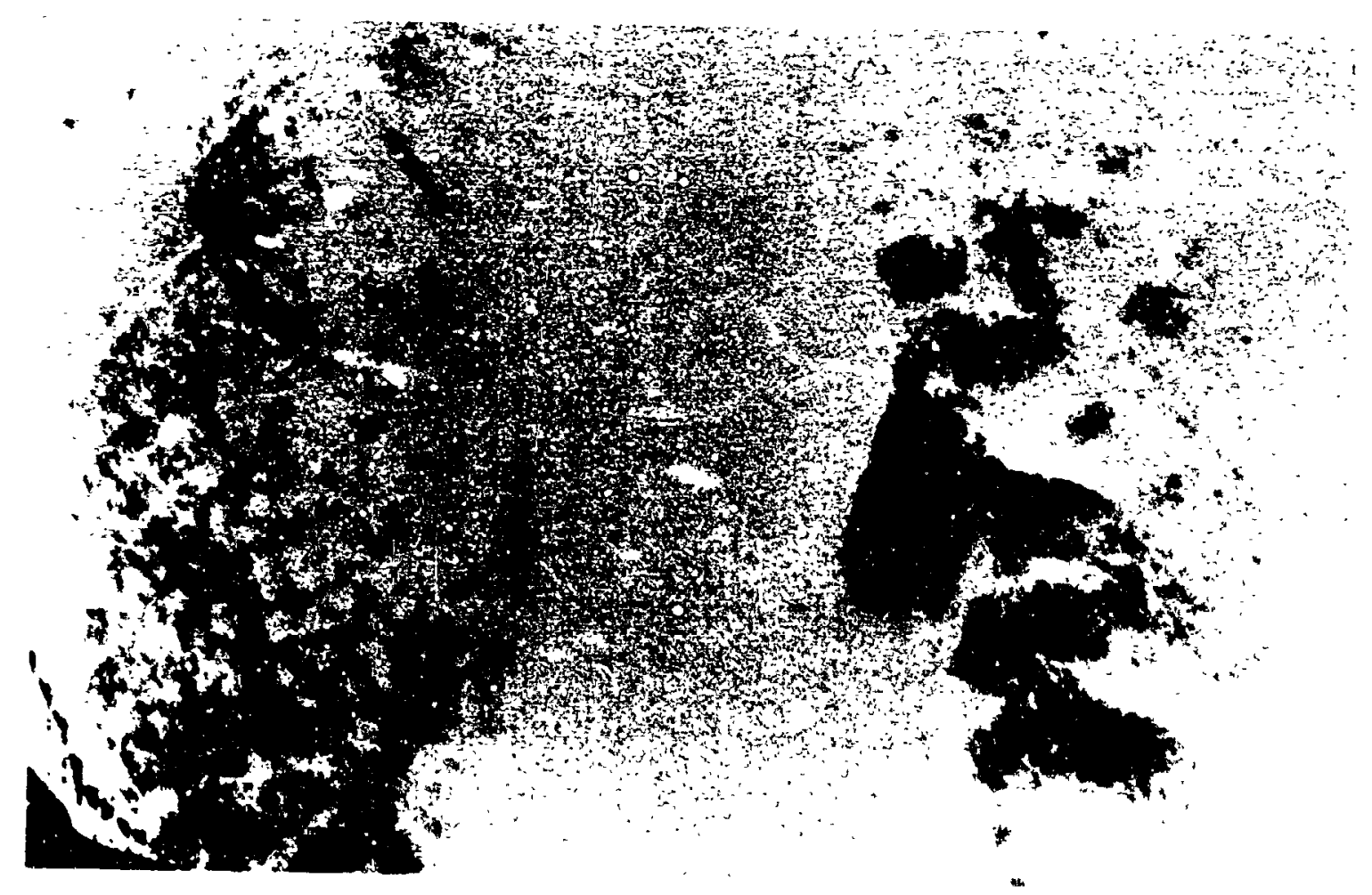

Fig. 7. Absolute-difference picture after correction program 


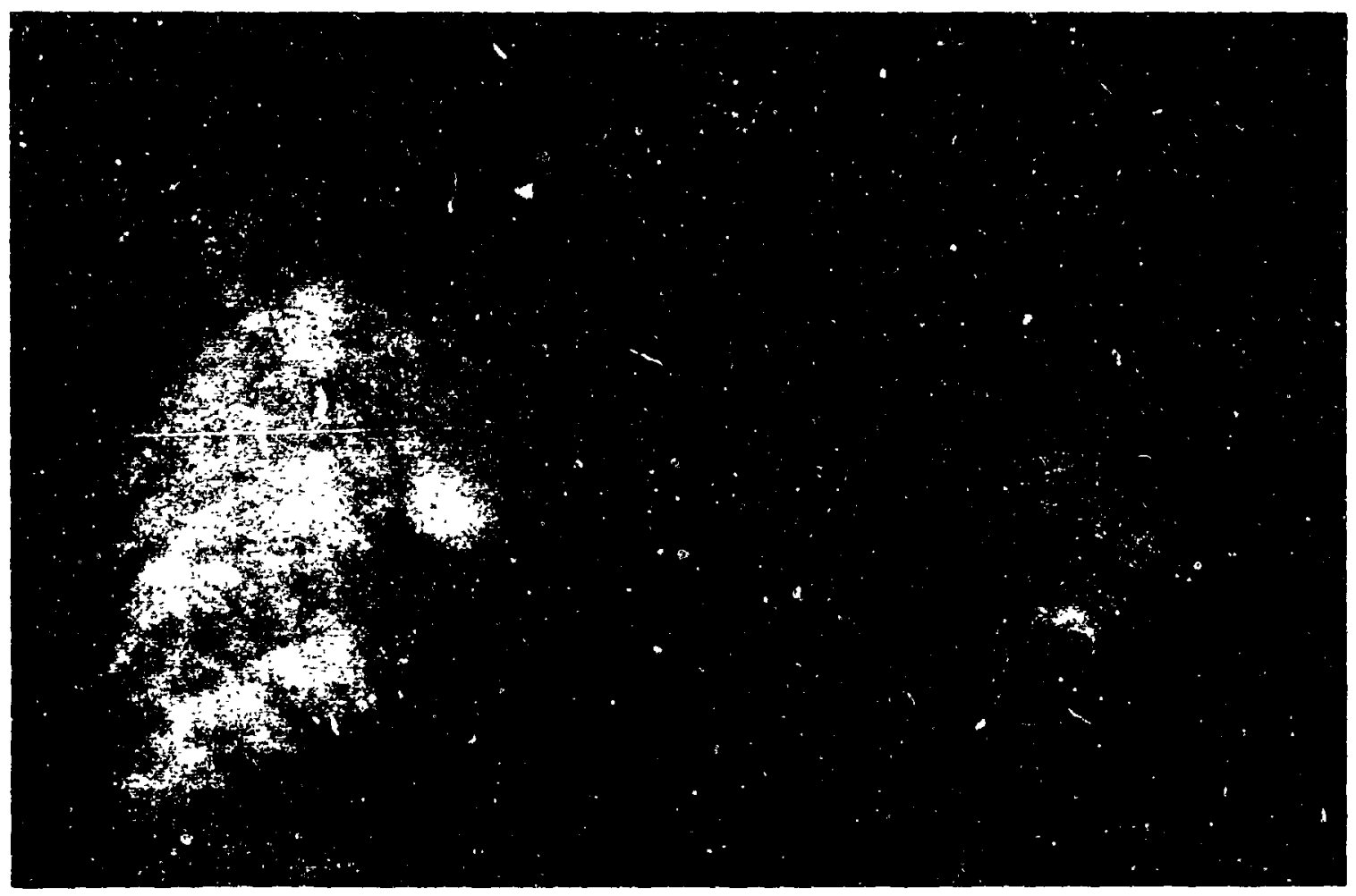

Fig. 8. X-Ray of chest taken September 1954, after high-pass filter
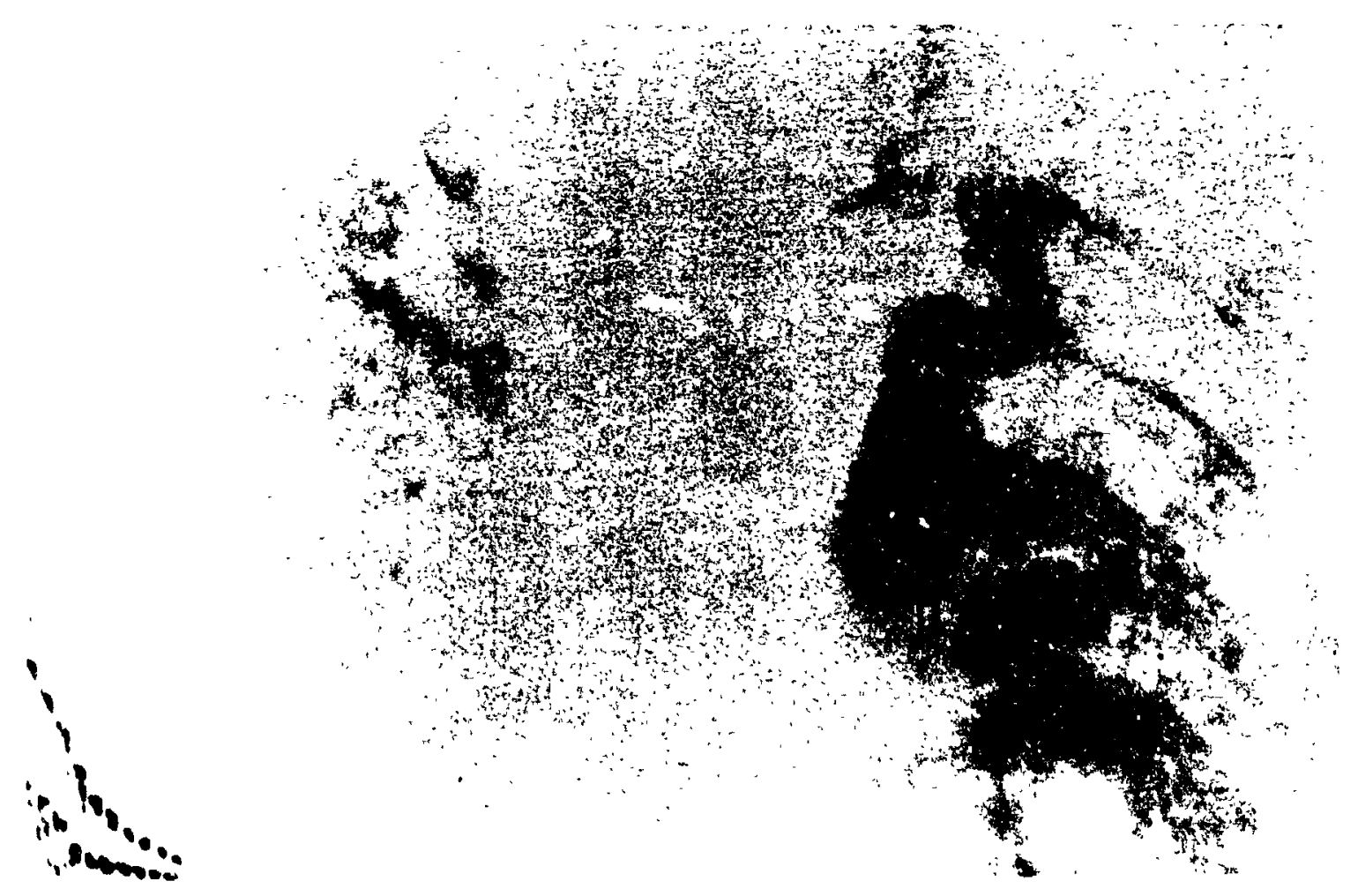

Fig. 9. Result of subtracting chest $x$-ray of Februnry 1954 from $x$-ray of September 1954 and selting negative differences to zero (white) 


\section{FREQUENCY-RESPONSE ENHANCEMENT}

The second image-enhancement technique to be described uses two-dimensional digital filters to effectively modify the frequency spectrum of the picture. Considerable attention has been devoted to measuring the frequency response of $\mathrm{x}$-ray systems in terms of the modulation transfer function, which gives the relative respol, re of the system as a function of spatial frequency in cycles per millimeier. A typicn! modulation transfer function of an $x$-ray system is shown in Fig. 10(a). The high-frequency falloff is caused by a number of factors that have been extensively studied. For example, the random distribution of $x$-ray quanta on a fluorescent intensifying screen causes a mottled effect that decreases system resolution. Similarly, the non-zero width of the $\mathrm{x}$-ray source causes a high-frequency loss because of a penumbra effect. Loss may also be due to numerous other causes, such as diffusion and bounceback in intensifying screens, film graininess, and radiation scatter.

As indicated in Fig. 10(a), the higher the frequency of the pictorial information, the lower the relative amplitude. At some frequency, this amplitude becomes so small relative to the background noise-which is more or less independent oi frequency-that the picture signal is irretrievably lost. However, just below this frequency there often exists picture information that is invisible because of its low amplitude but which is present in the picture and is recoverable.

The recovery method is based on the use of a digital filter whose transfer function, shown in Fig. 10(b), is the reciprocal of the modulation transfer fuinction of the $x$-ray system. The resultant overall system transfer function is then, as shown in Fig. 10(c), essentially flat out to some cutoff frequency. The cutoff frequency chosen is the highest possible without undue emphasis on background noise.

A sample is digitally filtered by calculating a weighted average of the surrounding samples-the weights determining the eftective filter transfer function. In turn, the weights are determined by sampling the Fourier Transform of the desired transfer function, an example of which is shown in Fig. 10(b). An infinite number

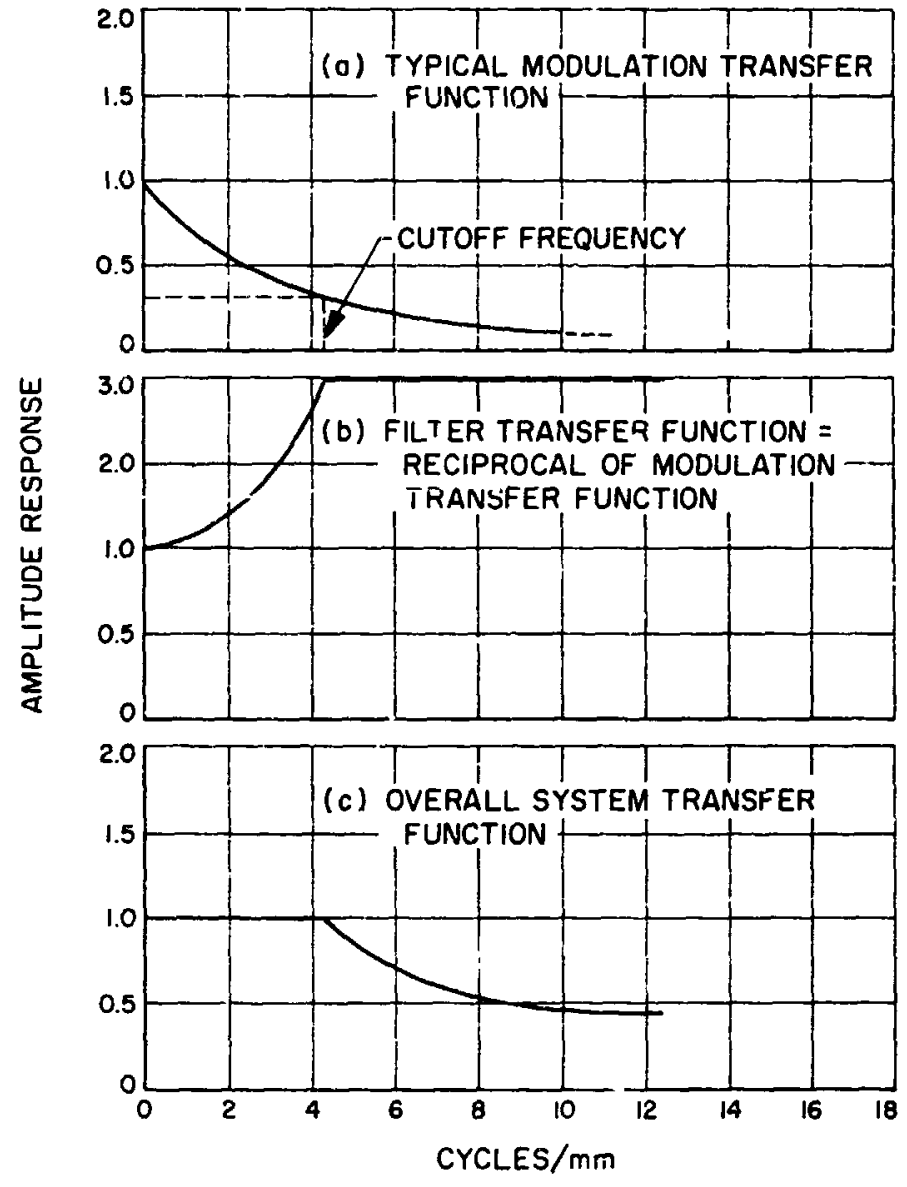

Fig. 10. Effect of filter on system transfer function

of weights gives the exact filter transfer function and a truncated series gives an approximation. All of the pictures to be discussed were filtered by a 15-by-15 array of weights which were generally sufficient to produce a filter to within one percent of that desired.

Figures 11 through 16 show examples of filtered pictures. The first is a skull $x$-ray showing the unprocessed picture in Fig. 11 and the filtered picture in Fig. 12. A general sharpening of the image is shown. Similarly, an infrared photograph of a diseased foot in Figs. 13 and 14, and a microscope photograph of a chromosome in Figs. 15 and 16 show the improvement in resolution after filtering. 
JPL TECHNICAL. REPORT NO. 32-1028

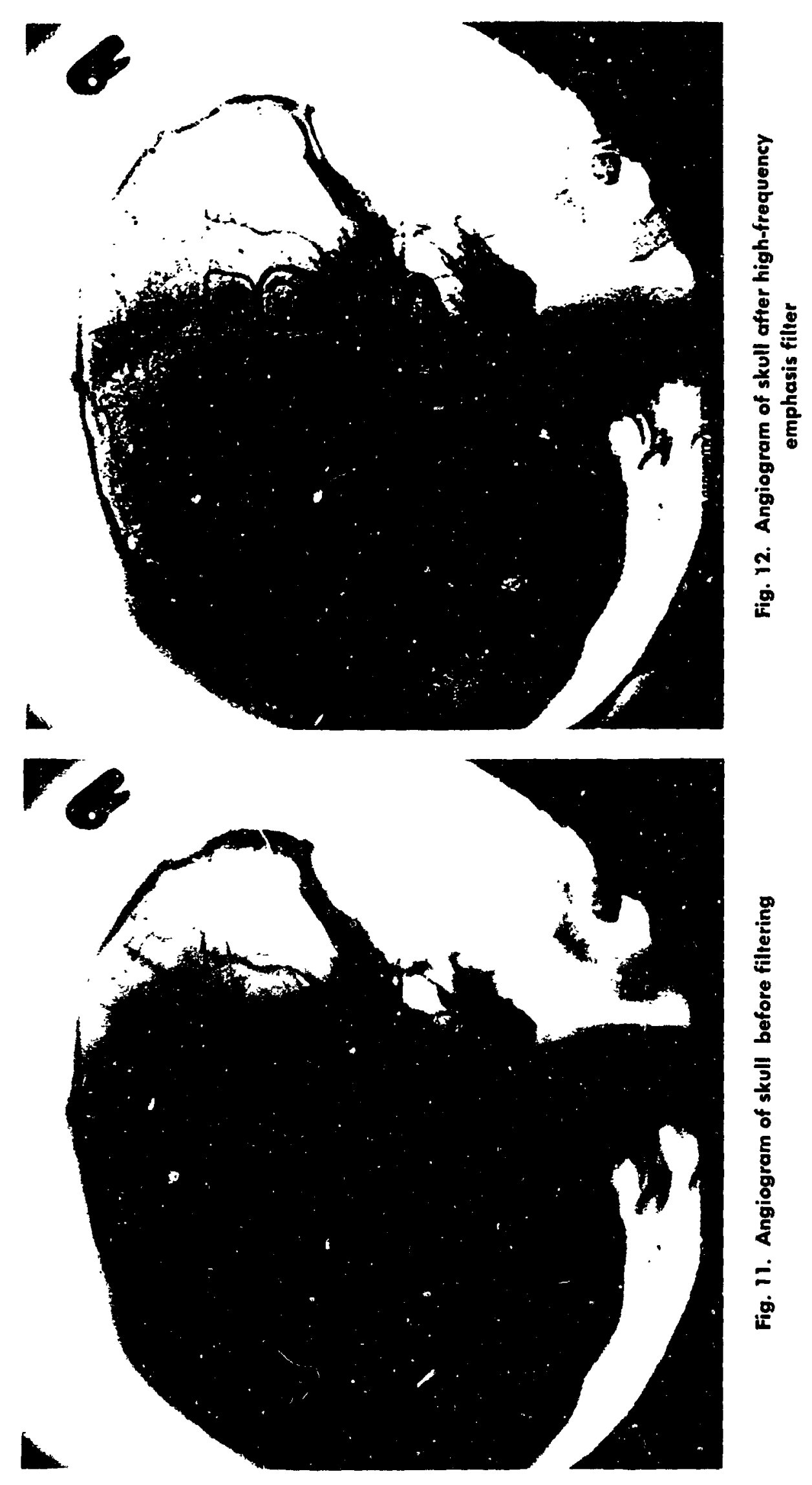


JPL TECHNICAL REPORT NO. 32-1028
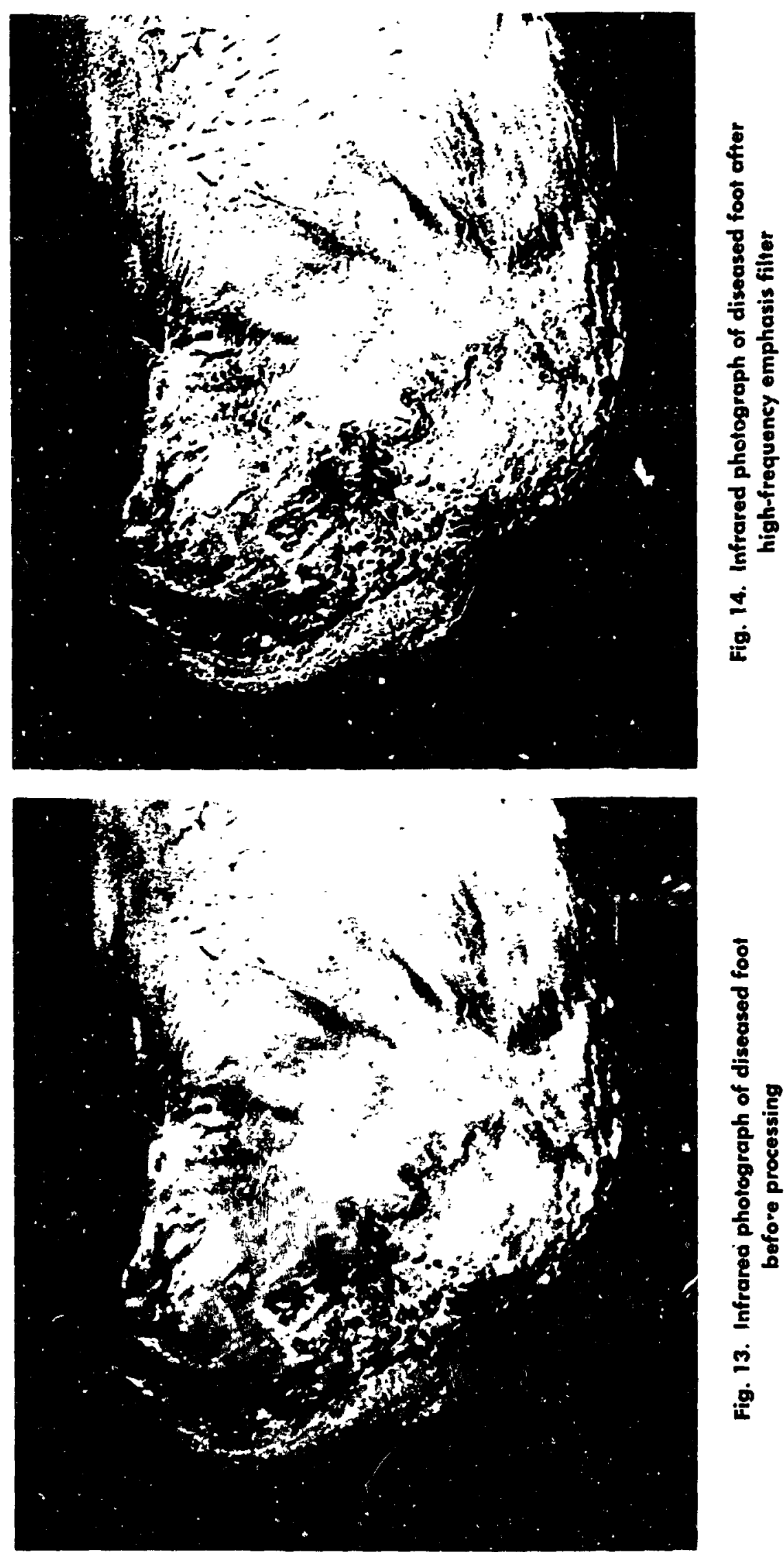

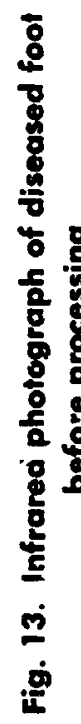



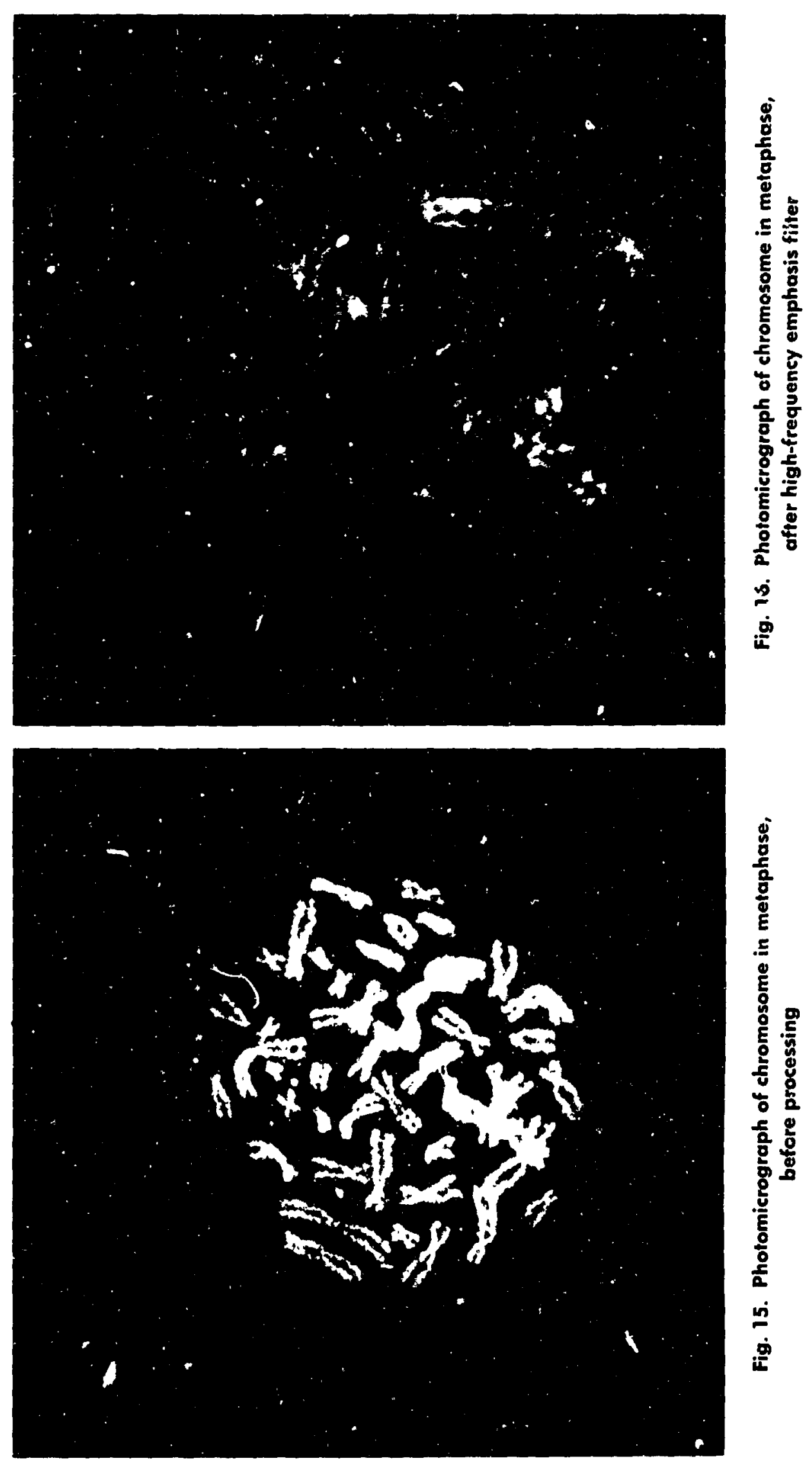
A better insight into the way in which the highfrequency emphasis filter works can be obtained by viewing the process as a high-pass filter, as shown in Fig. 8. The top curve shows a high-frequency signal superimposed on a low-frequency signal. The assumption is that the low-amplitude, high-frequency signal will not be seen against the large dark-to-white excursion of the other signal. Direct contrast enhancement as shown in Fig. 17(b) simply causes loss of the high-frequency signal because of saturation. Instead, as shown in Fig. 17(c), it is necessary first to remove some of the low-frequency signal using a high-pass fiiter; and then to increase contrast for effectively emphasizing the high-frequency signal.

A rather extreme high-pass filter was applied to the skull $x$-ray as shown in Figs. 18 and 19. The objective was to bring out the blood vessels lost in the highly exposed frontal portion of the skull. This filter removed all dc signai and a proportion of all low-frequency information. As seen, the fronta! blood vessels were clearly enhanced although at the cost of some distortion in the rest of the picture. A less extreme filter, perhaps one that removed three-quarters of the dc signal, would probably accomplish the same objective and, at the same time, maintain more of the original pictorial integrity.

A rather surprising result was obtained when this filter was applied to a mastoid $x$-ray. The section filtered is shown in Figs. 20 and 21. Figure 21 is a digitized version of the area indicated by the box in Fig. 20. Our intent was to bring out the mastoid structure beneath the denser bone toward the front but, as seen in Figs. 21 and 22 , tha signal-to-noise ratio was too low in this area for us to achieve our objective. However, in Fig. 22 minute detail of the mastoid structure suddenly became visible. This kind of detail could be very useful for detecting the presence of fluid in the cells.
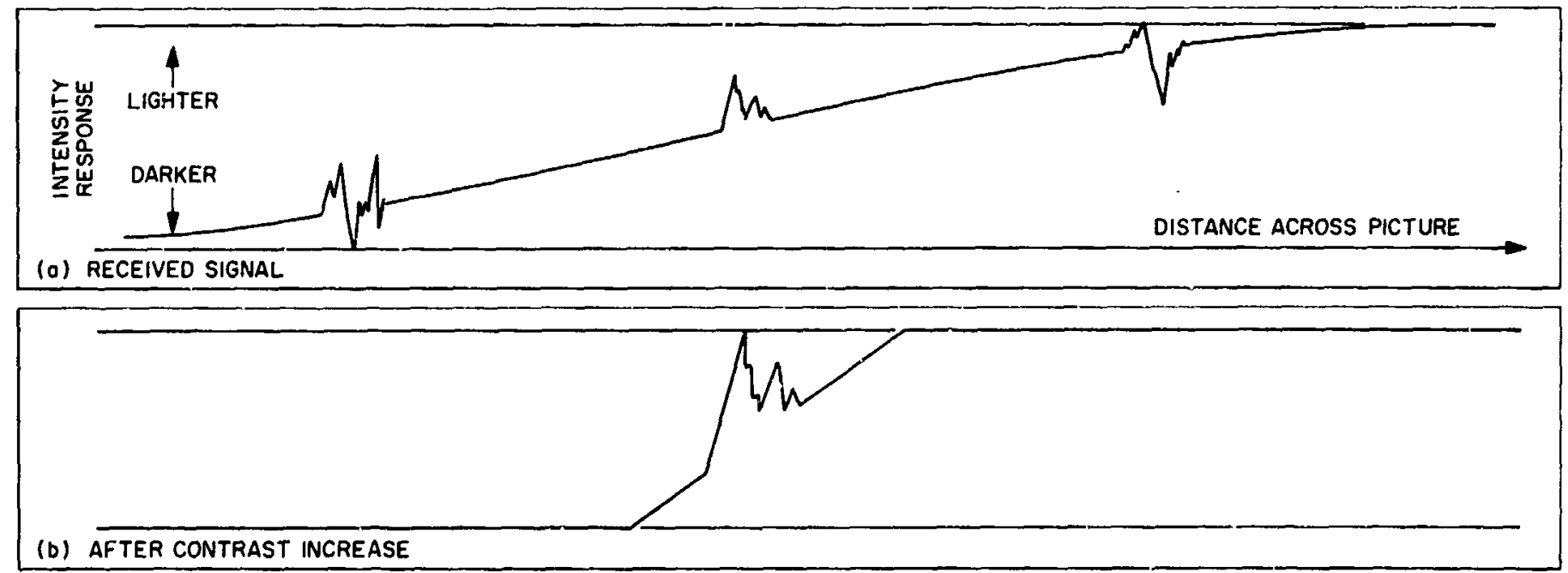

(b) AFTER CONTRAST INCREASE

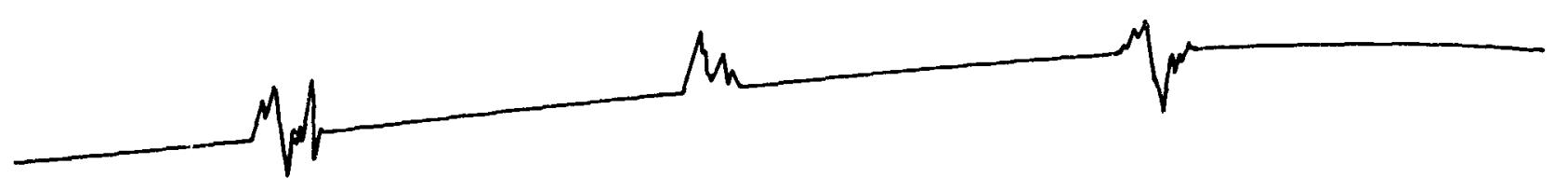

(c) AFTER HIGH-PASS FILTER

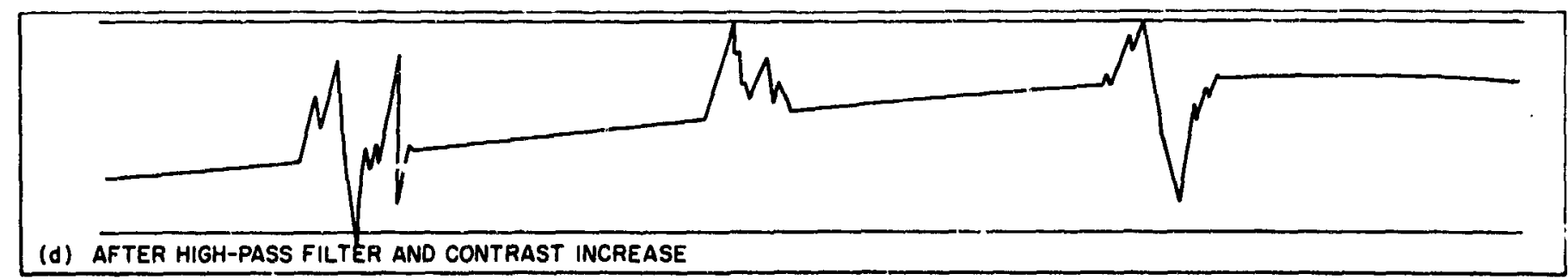

Fig. 17. Effoct of high-pass filter 

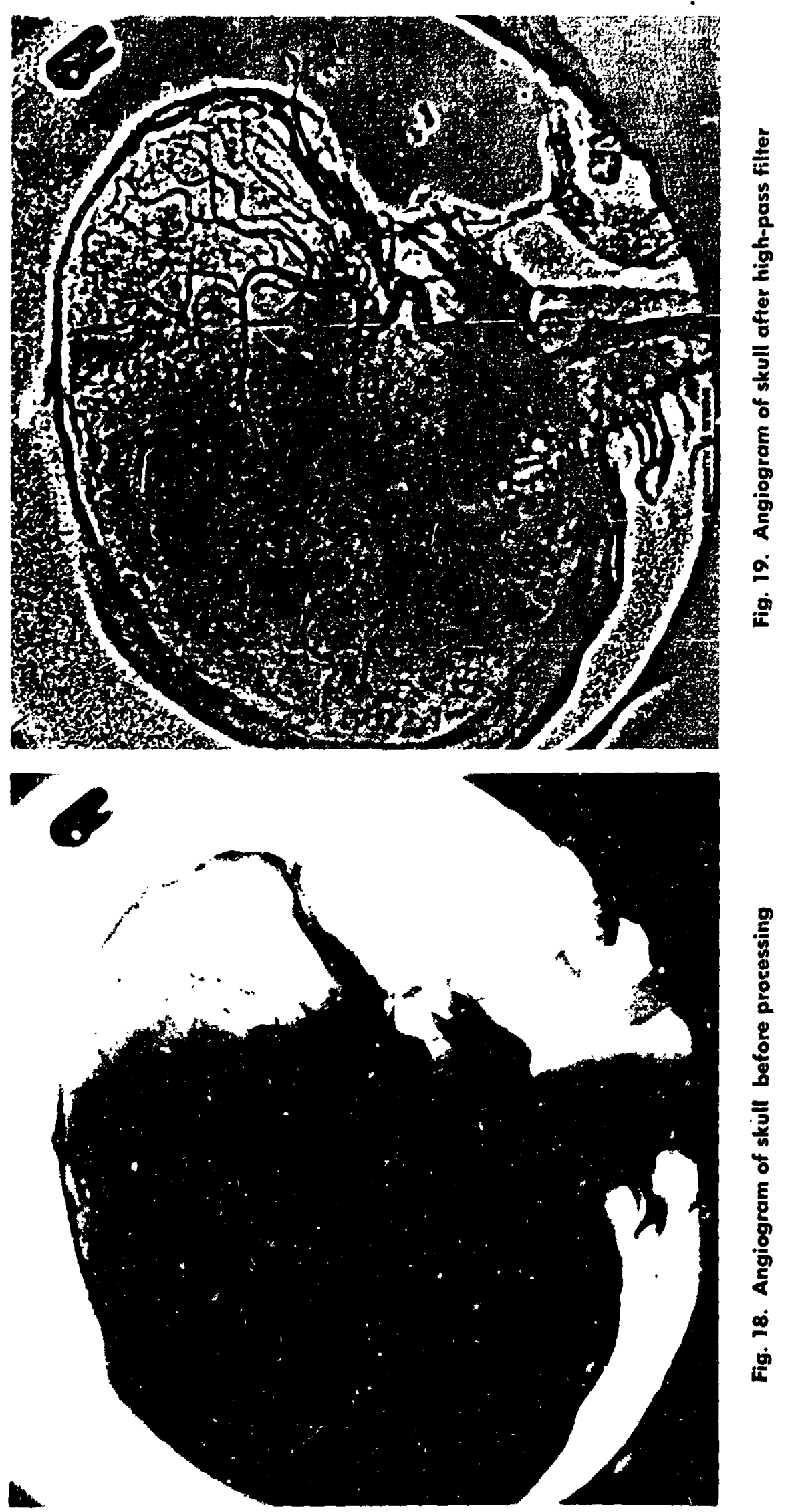
JPL TECHNICAL REPORT NO. 32-1028

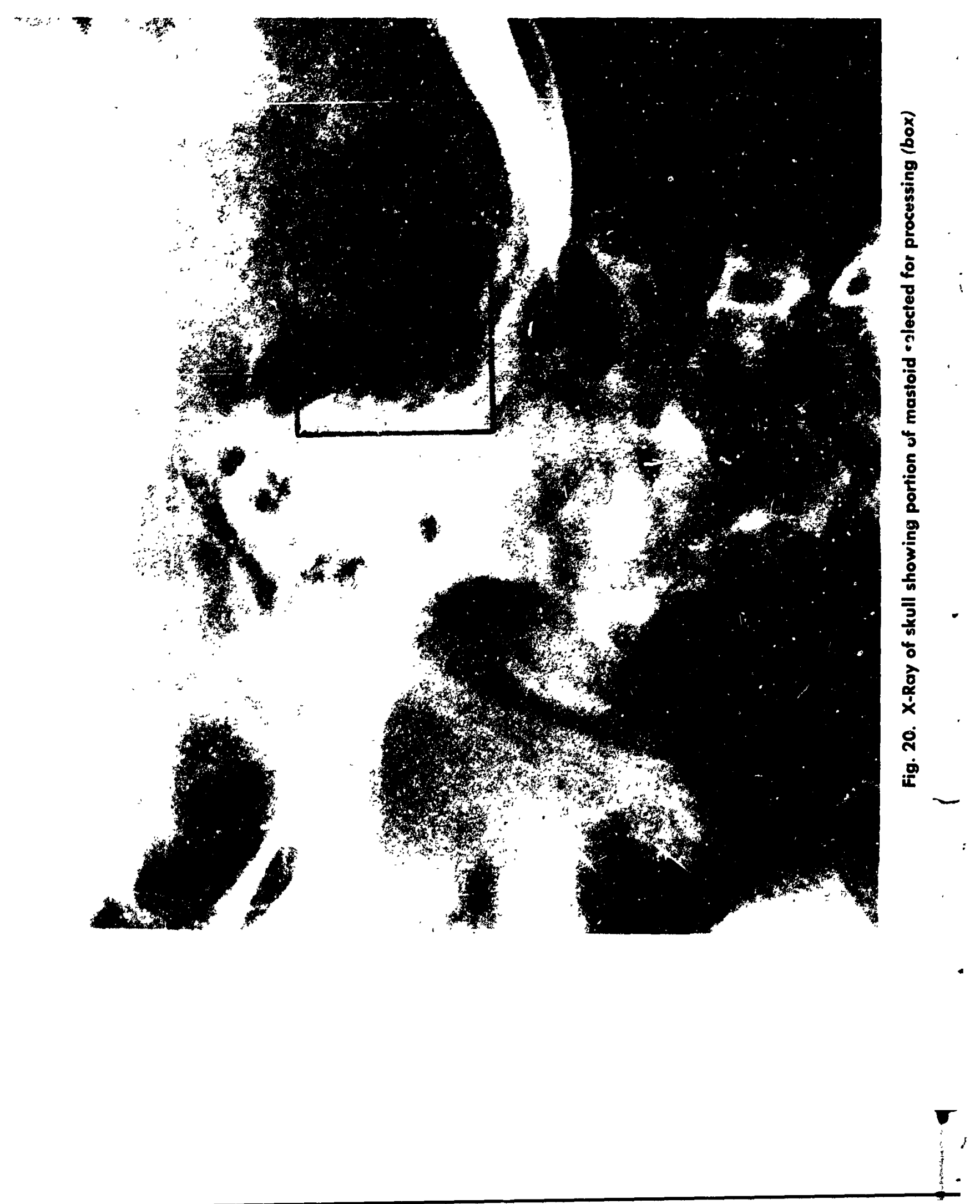



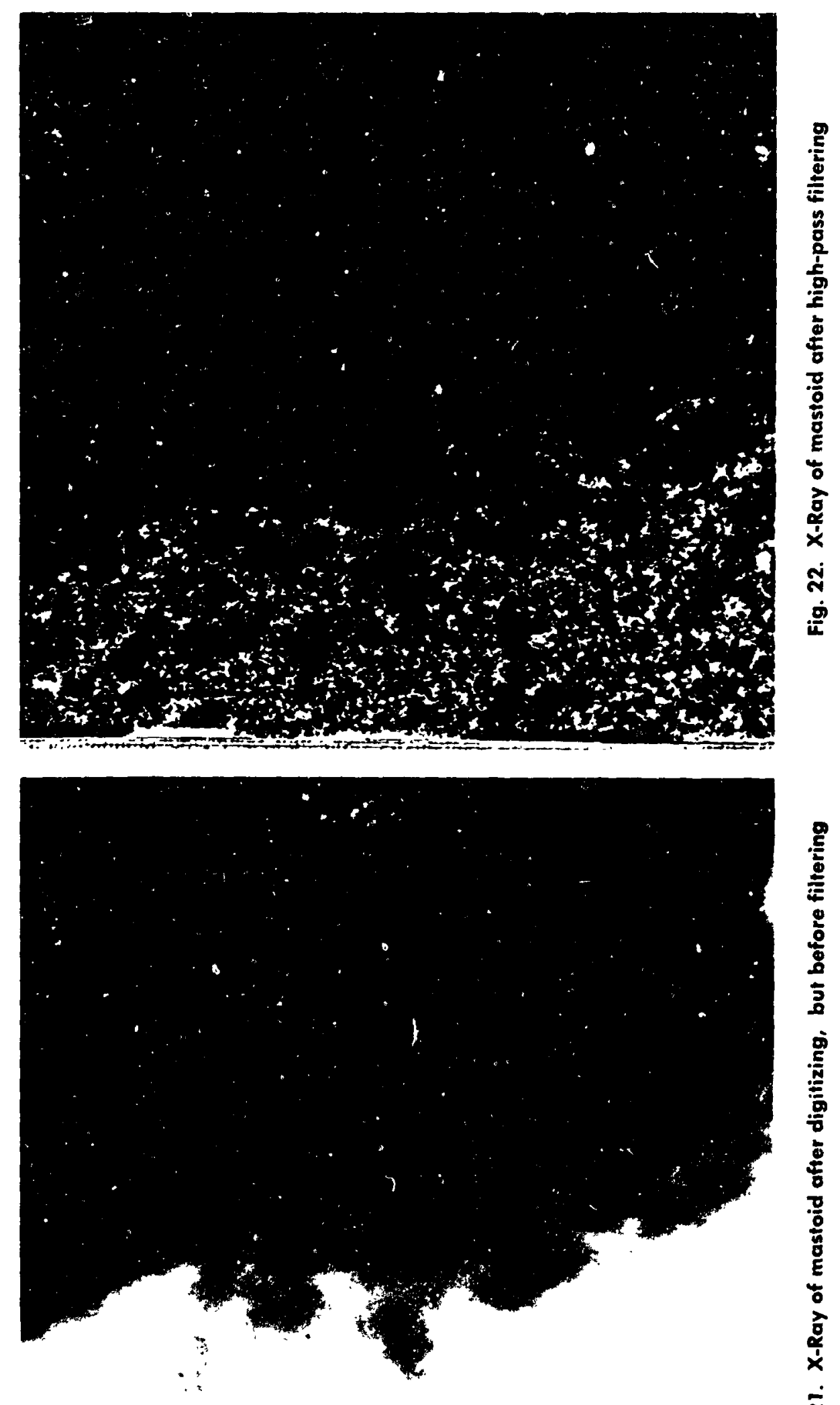


\section{CONCLUSIONS}

The purpose of the work to date has been to demonstrate the general capability of the computer to process medical and biological photographs. The next step is to apply these techniques to problems of specific medical value. Ir. addixion, a general investigation in the following are as should proceed:

Color uork. Processing of color pictures can easily be accomplisned by digitizing and processing each color component separately and then recombining components.

Nonsymmetric filtering. Filters with different transfer functions in the horizontal and vertical directions could be extremely useful. For example, a picture of a suspected hairline fracture with a known direction could be enhanced by applying a filter tha: emphasized low frequencies in the direction of the fracture and high frequencies perpendicular to that direction.
On-line operation. A computer tied directly to a film scanner, and having an instantaneous pictorial display of pictures stored in its memory, could decrease the time required to perform an operation such as subtraction from days to minutes, because a human operator viewing the match could adjust parameters on-line and accomplish the match very rapidly. Such a computer system is currently being assemiltd at Jet Propulsion Laboratory and should be fully operating early in 1967.

Spectral anaiysis. To effectively perform image enhancement by filtering, it is necessary to obtain better correlation hetween subjective visual quantities such as texture or pattern and a quantitative descriptor such as the two-dimensional Fourier spectrun. Thus spectral analysis on many different types of $\mathrm{x}$-ray photo; would be desirable.

\section{REFERENCES}

1. Nathan, R., Digital Video-Data Handling, Technical Report 32-877, Jet Propulsion Laboratory, Pasadena, California, January 5, 1966.

2. Highleyman, W. H., "Linear Decision Functions with Application to Pattern Recognition," Proceedings of the Institute of Radio Engineers, vol. 50, pp. 1501-1514, June 1962.

3. Sebestyen, George S., "Recognition of Membership in Classes," IRF Transactions on Information Theory, vol. 17.7, pp. 44-50, Janur, y 1961.

4. Butler, J. W., Butler, M. K., and Stroud, Agnes, "Automatic Classification of Chromosomes-III," in the Proceedings of the 1966 Rochester Conference on Data Acquisificn and Processing in Biology and Medicine. Pergamon Press, to be published early in 1967.

5. Lodwick, G., Keats, T. E., Dorst, J. P., "The Coding of Roentgen Images for Computer Analysis as Applied to Lung Cancer," Radiology, vol. 81, no. 2, August 1963.

6. Meyers, P. H., et al., "Evaluation of a Compiter-Retrieved Radiographic Image," Radiology, vol. 81, no. 2, pp. 201-206, August 1963.

7. Potsaid, M. S., Swanlund, C. D., King, G. E., and Neuberger, A., "Computer Analysis of Radiographs," Lippincott's Medical Science, vol. 17, no. 3, pp. 35-43, March 1966.

8. Hanafee, W., and Stre ", P., "Subtraction Technic," Radiology, vol. 79, no. 4, pp. 658-661, Octo - i१ 2. 


\section{REFERENCES (Cont'd)}

9. Ludovico, N., "Subtractive Interference Technique in Radiography," Radiograptia, no. 8, pp. 169-1 1.5, Merch 1964.

10. Margan, R. H., Bates, L. M., Gopalarao, U. V., and Marinaro, A., "The Frequency Response Characteristics of X-Ray Films arid Screens," The American Journal of Roentgenology, Radiation Thercipy and Nucleur Medicine, vol. 92, pp. 426-440, August 1964.

11. Morgan, R. H., "The Frequency Response Function," The American Journal of Roentgenology, Radiotion Therapy and Nuclear Mediciri, vol. 88, no. 1, pp. 175186, July 1962.

12. Rossman, K., "Spatial Fluctuations of X-Ray Quanta and the Recording of Radiographic Mottle," The American Journal of Roentgenology, Radiotion Therapy and Nuclear Medicine, vol. 90, no. 4, pp. 863-880, October 1963.

13. Hoim, Thure, "Some Aspects of Radiographic Information," Radiology, vol. 83, no. 2, pp. 319-327, August 1364.

14. Rossman, K., "Modulation Transfer Function of Radiographic Systems Using Fluorescent Screens," Journal of the Optical Society of America, vol. 52, no. 7, pp. 774777, July 1962

15. Rossman, K., "Image-Forming Quality of Radiographic Screen-Film Systems; The Line Spread-Function," The American Journal of Roentgenology, Radiation Therapy and Nuclear Medicine, vol. 90, no. 1, July 1963. 


\section{APPENDIX}

Because of spicce limitations. not all of the pictures that were contributed for processing could be incorporated into this R(pori. However, since all of the submitted pictures were extremely helpful in the establishment of the computer techniques, they have been included in the list below.

$X$-Rays (single frames)

Osteoporosis in the knee. Donald Deselits, MD, Department of Radiology, University of California, Los Angeles

Chest concer.

William Weiss, MfD, Director, Philadelphia Pulmonary Neoplasm Research Project

Aor:ic aneurysm.

C. Murpli!: MD, George W'ashington University Hospital, Washington, D.C.

Skull circulation.

Amos Norman, PhD. Department of Radiology, University of California, Los Angeles

Polytone ear pictures.

Joseph L. Westover, MD, Department of Radiology, University of California, Los Angeles

X-Rays (moving pictures)

Heart circuiation.

Russell H. Morgan, MI), Johns Hopkins Hospital. Baltimore

\section{Gamma Rays}

Luns cancer, Scan Method. W. Tauxe, MD, Mayo Clinic, Rochester

Infrared Photography

Discased foot.

Davic! Bendersky; BSME, Jlead Engineer, Mechanical Section, Mfidwest Research Institute, Kansals City, Missouri

Photomicrograph

Chromosomes.

Amos Norman, PhD, Department of Radiology. University of California, Los Angeles

\section{Direct Photography}

Retina tumors.

Itcrmin Weiss, MD, Ophthalmologist, Beverly Hills, California 


\section{ACKNOWLEDGMENT}

This work was done in collaboration with Dr. Robert Nathan of Jet Propulsion Laboratory and with the encouragement of the NASA Technology Utilization Division. The author would also like to thank those persons listed in the Appendix who provided photographs for processing. 